\title{
FATAL GENERALIZED VACCINIA WITH FAILURE OF ANTIBODY PRODUCTION AND ABSENCE OF SERUM GAMMA GLOBULIN
}

\author{
BY
}

\author{
S. E. KEIDAN, K. MCCARTHY and J. C. HAWORTH \\ From the Departments of Bacteriology and Child Health of the University of Liverpool and Alder Hey Children's Hospital
}

(RECEIVED FOR PUBLICATION NOVEMBER 3, 1952)

The reaction to vaccination against smallpox is generally a trivial, short-lived affair. Complications are uncommon and, of these, generalized vaccinia is one of the least common. In true generalized vaccinia the lesions pass through the stages of papule, vesicle and pustule with little cropping, and the first lesions seldom occur earlier than the ninth day after vaccination. In most cases the disease is self-limiting, the lesions heal normally, and neutralizing antibodies develop during the course of the disease. A small number of cases have been reported, however, in which lesions continued to develop over a period of weeks or months. Nearly all of these have been fatal. A further case of this type is reported here.

\section{Case Report}

E.H., a girl, was born by normal delivery at full term on September 24, 1951, and weighed $6 \mathrm{lb}$. $5 \mathrm{oz}$. at birth. The parents, who were first cousins, were quite healthy. The mother had been unsuccessfully vaccinated in infancy and had not been re-vaccinated. The father had been successfully vaccinated in infancy and re-vaccinated in 1944. This resulted in a normal reaction. The only sibling had died at the age of 5 months from bronchopneumonia and had not been vaccinated. The baby had been breast fed for four weeks and was then weaned on to 'lacidac'; supplements of cod liver oil and ascorbic acid had been given, and up to the time of vaccination she had been very well and gaining weight normally.

E.H. was vaccinated on the left deltoid region on November 22, 1951, at the age of 8 weeks. A small vesicle was visible on the vaccination site one week later and two weeks after vaccination further vesicles were observed around the primary lesion. Several others were noticed around the vulva and anus about the same time. Seventeen days after vaccination a small vesicle developed on the dorsum of the left hand. The child had mild diarrhoea following the vaccination but had taken her feeds well and had not been vomiting.

She was admitted to Alder Hey Children's Hospital on December 13 at the age of 11 weeks. Examination showed a healthy-looking infant with a good colour, weighing $8 \mathrm{lb}$. $8 \frac{1}{2} \mathrm{oz}$. The rectal temperature was 99: F. At the vaccination site on the left deltoid region was a yellowish ulcerated area $2.5 \mathrm{~cm}$. in diameter surrounded by numerous vesicles, varying in size from 5 to $20 \mathrm{~mm}$. in diameter, and containing clear fluid (Fig. 1). A number of large umbilicated vesicles surrounded the vulva and

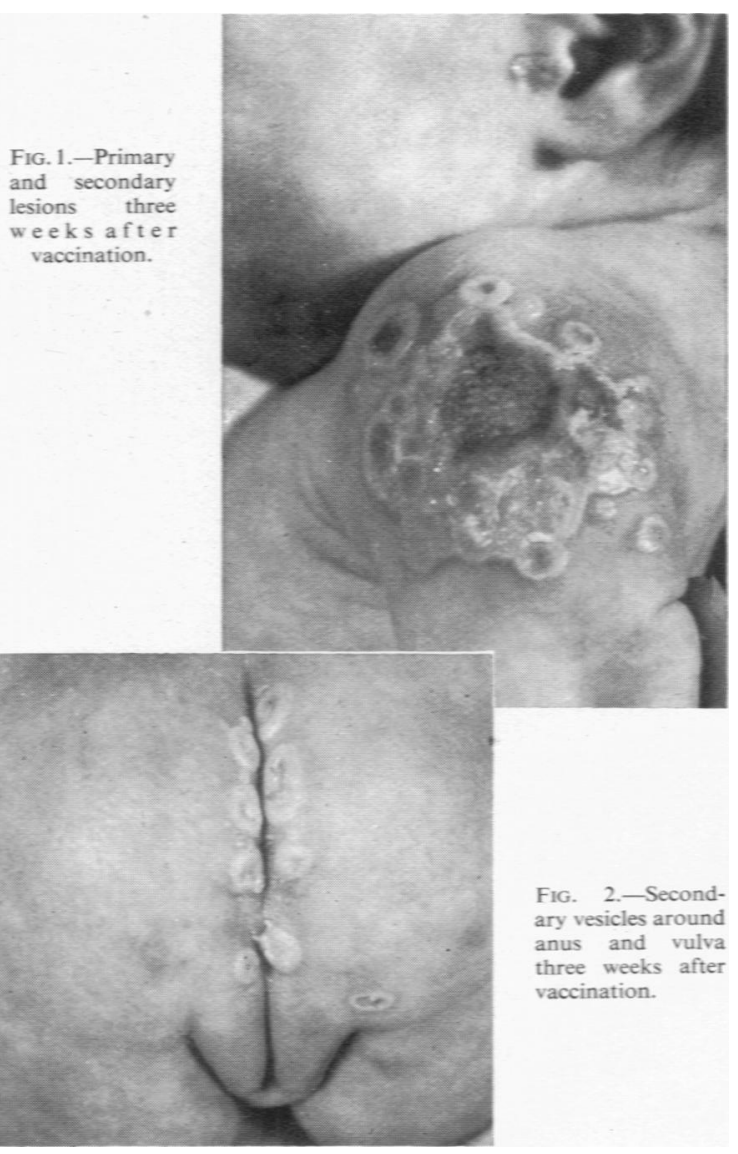


anus (Fig. 2). Other single vesicles were on the upper lip, the right side of the face, the dorsum of the right hand (Fig. 3), the right leg, the left heel, and there were a few lesions on the back. No lesions were seen in the mouth. Neither the spleen nor any lymph nodes were palpable. A provisional diagnosis of generalized vaccinia was made.

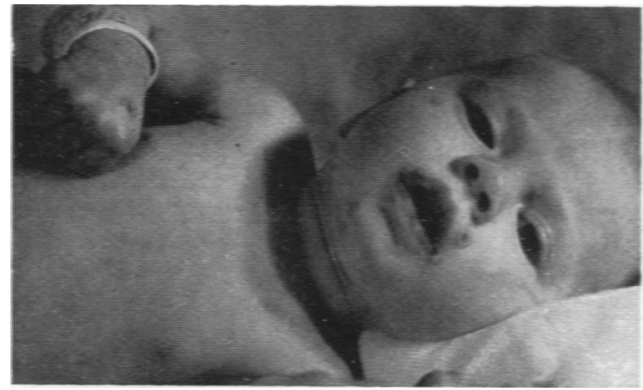

FiG. 3.-Lesions on the face and the right hand three weeks after vaccination.

From the time of her admission until her death four weeks later there was steady deterioration in her condition. The vesicles on the left deltoid area coalesced and eventually formed a large ulcer with a granulating base and rolled vesicular edge (Fig. 4). Vesicles continued to appear on the face, scalp and the rest of the body in a centrifugal distribution. Many of the lesions coalesced and, like the primary lesion, formed large, spreading

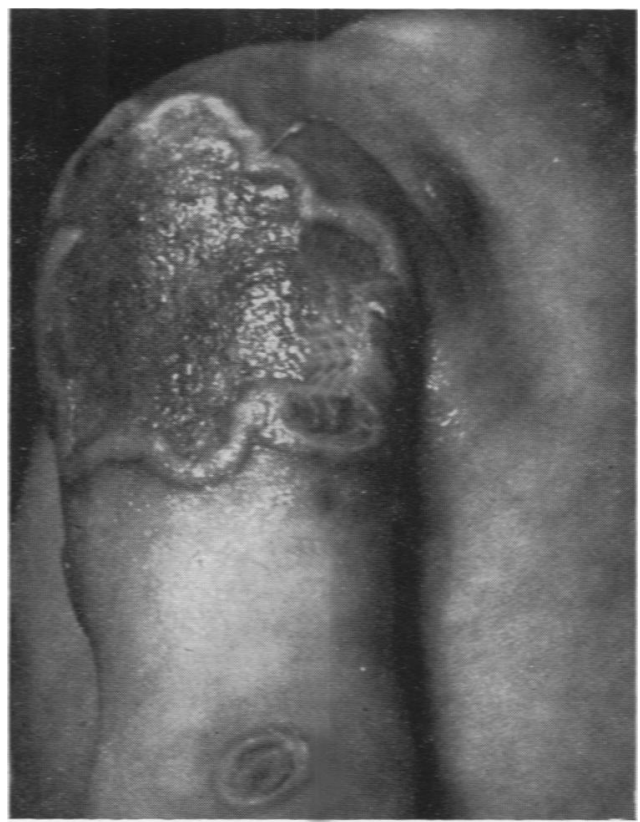

FK. 4.-Primary lesion five weeks after vaccination. Secondary lesions at various stages of development can be seen on the scapular region and the arm. ulcers. Lesions in the nostrils led to nasal obstruction and interfered with feeding. The eyelids became involved two weeks before death but the eyes themselves were not affected (Fig. 5). In the mouth ulcers appeared on the tongue, the palate and the cheeks. The cry became hoarse and laryngeal involvement was suspected. None of the lesions ever showed any signs of healing and there was little evidence of infla mmatory reaction except for an area of cellulitis surrounding deep ulcers on the left foot The spleen and lymph nodes were never enlarged. There

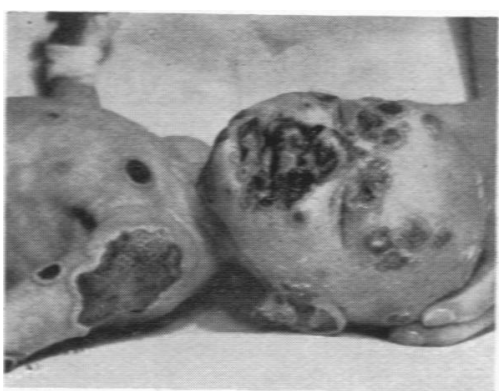

Fig. 5.-Spreading lesions on the face six weeks after vaccination. was little fever, the rectal temperature rarely exceeding $100=$ F. Feeds were taken poorly and she developed diarrhoea during the last fortnight. She steadily lost weight and was only $6 \mathrm{lb} .9 \mathrm{oz}$. shortly before death.

Investigations. Blood culture on December 24 showed a profuse growth of Staphylococcus aureus (coagulase positive) and enterococci. The staphylococcus was sensitive to chloromycetin and aureomycin and slightly sensitive to penicillin. On January 2 Staphylococcus aureus (coagulase positive) was cultured.

The Wassermann reaction was negative.

A swab from infected skin lesions taken on December 27 gave a profuse growth of Staphylococcus aureus (coagulase positive).

On January 1, 1952, following transfusion, a full blood count gave: haemoglobin, $96 \%$; leucocytes 6,700 per c.mm. (corrected) (myelocytes, 871 or $13 \%$, band cells, 871 or $13 \%$, polymorphs, 4,221 or $63 \%$ lymphocytes, 134 or $2 \%$, monocytes, 603 or $9 \%$ ). Normoblasts were 55 per 100 leucocytes. The red blood cells showed anisocytosis, polychromasia and punctate basophilia.

On January 3 the leucocytes were 6,000 per c.mm. (metamyelocytes, 540 or $9 \%$, myelocytes, 60 or $1 \%$, band cells 3,840 or $64 \%$, polymorphs, 1,200 or $20 \%$, lymphocytes, 120 or $2 \%$, monocytes, 240 or $4 \%$ ).

Treatment. From the time of her admission penicillin, 250,000 units and later 125,000 units, was given sixhourly intramuscularly. Aureomycin, $100 \mathrm{mg}$. six-hourly by mouth, was given from December 27 until the time of death. Local treatment consisted of the application of penicillin powder and tulle gras to the skin lesions and $1 \%$ gentian violet to the mouth. On December $2260 \mathrm{ml}$. of serum from a recently vaccinated donor (A) was given intravenously. On December $31,250 \mathrm{ml}$. of whole blood from another recently vaccinated donor (M) was transfused after removal of $100 \mathrm{ml}$. of the child's blood to prevent circulatory overloading. On January 4, $500 \mathrm{mg}$. of gamma globulin was given intramuscularly and a further $250 \mathrm{mg}$. the following day. 
She died on January 6,1952 , seven weeks after vaccination.

Post-mortem Report. Post-mortem examination was made 18 hours after death by Dr. E. G. Hall. Inspection showed the wasted body of a female infant. Scattered over the skin of the whole body, but especially marked on the extremities and face, were numerous lesions ranging from minute vesicles to crusted ulcers. Lymph nodes throughout the body were of approximately normal size and did not show any macroscopic abnormality. Scanty minute petechiae were present on the visceral pericardium and the right auricle was dilated but otherwise the cardiovascular system was normal. There were ulcers on the tip and lateral borders of the tongue and a few on the soft palate. The laryngeal orifice was narrowed by oedema of the aryepiglottic folds spreading from an ulcer $5 \mathrm{~mm}$. in diameter, lying on the anterior surface of the laryngo-pharynx and immediately behind the arytenoid cartilage. In the lungs there was bilateral bronchopneumonic consolidation involving the lower lobes and portions of the upper and middle lobes. The liver was rather pale but otherwise normal. The spleen was small, firm and of normal colour. The right adrenal was completely destroyed by haemorrhage which extended into the extra-peritoneal tissues on that side, and there was a small haematoma, $5 \mathrm{~mm}$. in diameter, in the antero-medial aspect of the left adrenal. The brain showed slight congestion but was otherwise normal.

Histology. All tissues were fixed in formol Zenker for six hours and sections stained by haematoxylin and eosin and also by eosin and methyl blue.

A small piece of skin from the scalp, only 2 $\mathrm{cm}$. long, showed on section lesions in several stages of development ranging from an early focus, involving only a few cells, to a late lesion, beginning to crust. A typical early vesicle about $4 \mathrm{~mm}$. in diameter was present on the sole of the foot. Microscopic examination showed a vesicle situated fairly deeply in the epidermis. Inclusion material was present in large amounts in the surviving epithelial cells of the vesicle floor between the papillae of the corium. Many of these basal cells were full of strongly acidophilic cytoplasmic inclusion material with only a ghost of a degenerate nucleus discernible. One striking feature was an almost complete lack of infiltration by inflammatory cells (Fig. 6). These two features, lack of inflammatory response and large amounts of coarsely granular inclusion material, characterized all the skin lesions examined. One of the scalp lesions contained what appeared to be pus, but on examination this was found to be composed of epithelial debris with very few polymorphs. The lung showed congestion and oedema of the alveolar walls with very few inflammatory cells. The liver, kidney, brain and a salivary gland were also sectioned but showed no abnormality. A section of an axillary lymph node showed large numbers of monocytes and plasma cells. Germinal centres and lymphocytes were completely absent (Fig. 7). The spleen showed very few Malpighian corpuscles and those which were present were made up mainly of plasma cells and monocytes. No lymphocytes or lymphatic tissue were seen.

Virus Studies. On December 13, the day of admission to hospital, scrapings were taken from the base of a typical secondary vesicle. Smears made from these were fixed and stained by Gutstein's method using alkaline methyl violet. Large numbers of elementary bodies were present, indistinguishable from those seen in smears from cases of smallpox. Swabs were taken from a typical early

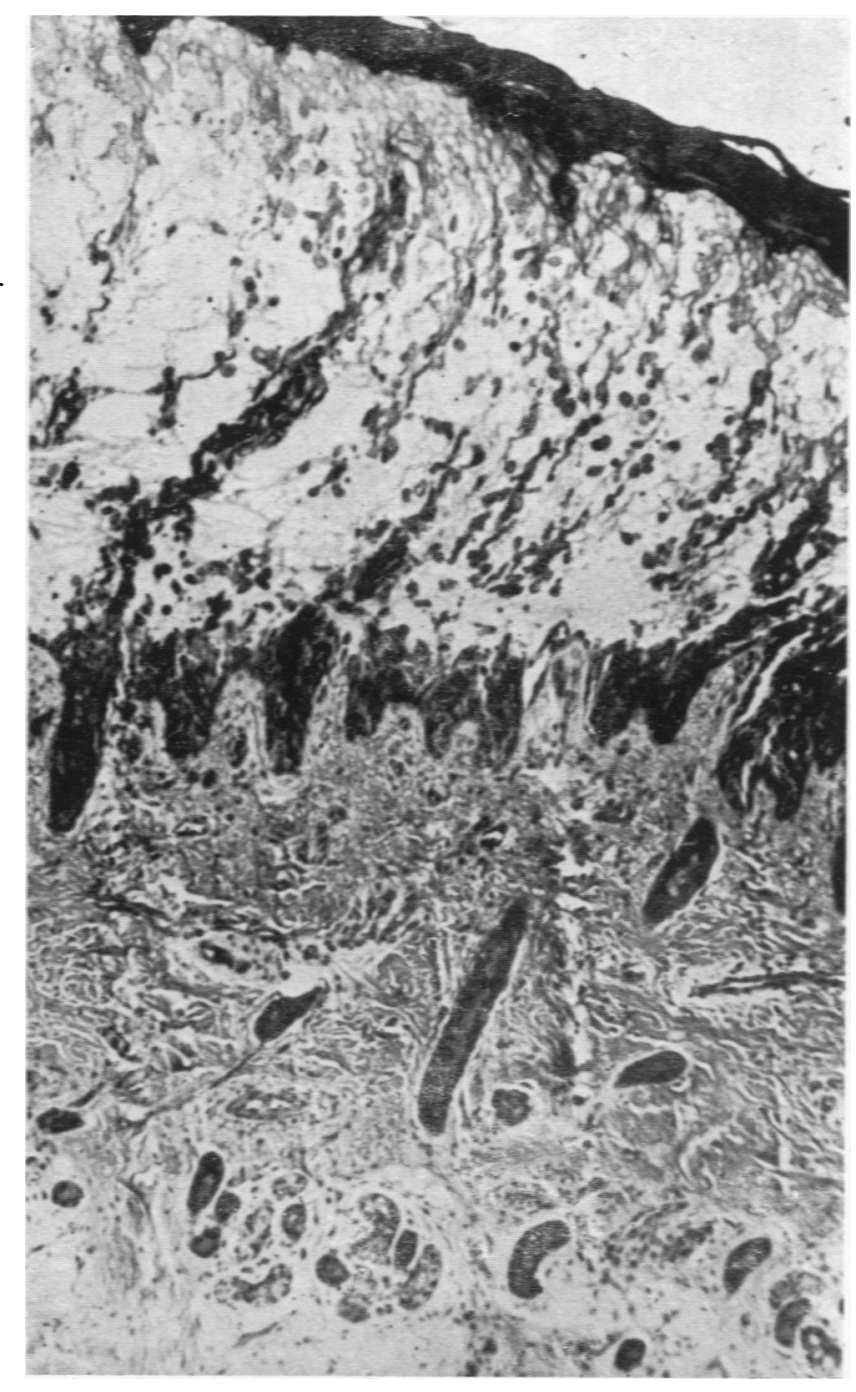

Fig. 6.-Section of vesicle from sole of foot showing absence of inflammator: cells in the dermis (low power haematoxylin and eosin). 
lesion on the face and from the base of one of the perianal ulcers. After treatment with antibiotics extracts in varying dilutions were inoculated on to the chorioallantoic membrane of 12-day chick embryos. Blood, obtained from the baby by jugular puncture on December 13, was divided into two parts, one of which was heparinized and the other allowed to clot. The heparinized whole blood was lysed by alternate rapid freezing and

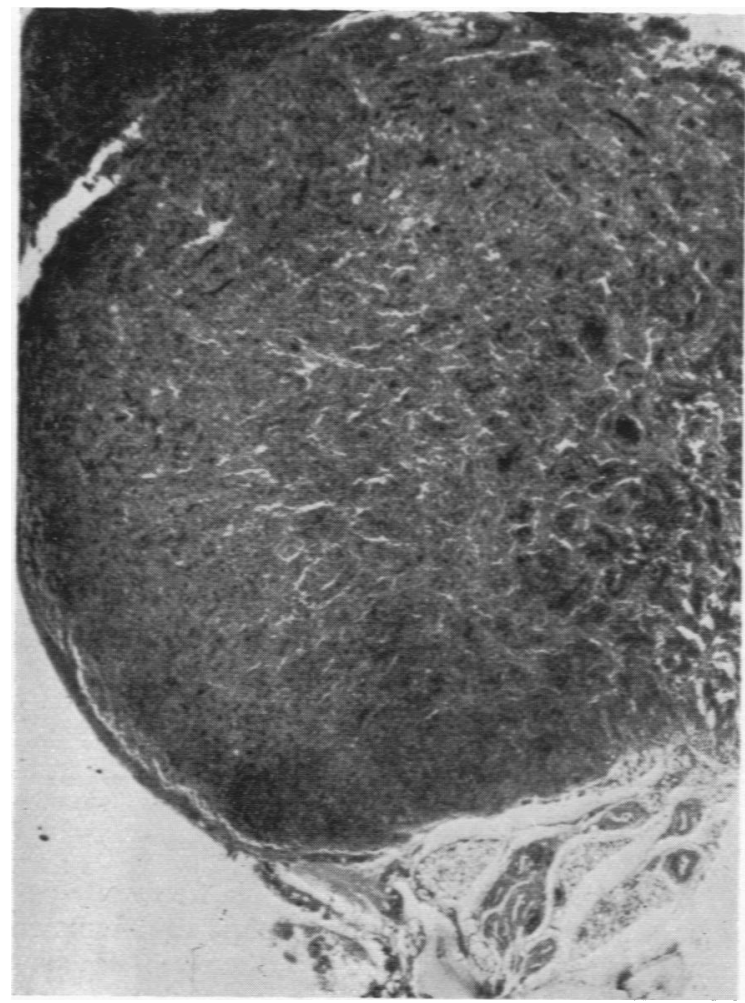

FiG. 7.-Section of axillary lymph node showing absence of germinal centres.

thawing in alcohol-solid $\mathrm{CO}_{2}$ and $0.4 \mathrm{ml}$. was then inoculated on to the chorio-allantois of each of four eggs. The serum was separated from the clotted blood and stored at $-78^{\circ} \mathrm{C}$.

After three days' incubation the eggs inoculated with the swab extract showed typical isolated vaccinial lesions from the higher dilution while the lower dilution showed confluent lesions. Microscopical examination of sections of confluent lesions showed proliferation of the ectodermal cells, which contained large amounts of acidophilic intra-cytoplasmic granular inclusion material when stained with eosin and methyl blue.

The pock counts in the four eggs inoculated each with $0.4 \mathrm{ml}$. of whole blood ranged from 20 to 30 so that more than 50 infective particles per $\mathrm{ml}$. must have been present in the child's blood at this time. The site of the venepuncture was free from visible skin lesions, nor did a skin lesion subsequently develop where the needle pierced the skin.

In addition to this first blood sample taken three weeks after vaccination, further samples of heparinized and clotted blood were obtained as follows:

18.12.51. Thirty infective particles (vaccinia virus) per $\mathrm{ml}$. were recovered from this heparinized blood sample.

23.12.51 (four weeks after vaccination). Five infective particles per $\mathrm{ml}$. were recovered. (This sample was taken 18 hours after administering $60 \mathrm{ml}$. of serum from a well vaccinated donor (A) whose serum was known to contain neutralizing antibody.)

31.12.51 (five and a half weeks after vaccination). One hundred and ten infective particles per $\mathrm{ml}$. were recovered. However, by this time cutaneous lesions were fairly widespread, and although there were no visible lesions at the site of the puncture, the skin may have become contaminated with virus from neighbouring lesions. Nevertheless, a viraemia was almost certainly present at this time, for skin lesions continued to appear up to the time of death one week later.

A further transfusion given on December 31 consisted of $250 \mathrm{ml}$. of homologous citrated whole blood taken three hours previously from a different donor (M). It was known from previous investigations of the sera of these two donors that there would be less antibody in serum (M) but it was thought that whole blood might be more effective, and this donor was of the same blood group as the baby.

7.1.52. The last sample of blood from the baby was obtained 18 hours after death. This was one week after administering the whole blood and two days after giving the gamma globulin. This sample was obtained after the body had been opened and skin contamination of the blood samples can be ruled out. Approximately 100 infective particles per $\mathrm{ml}$. were found.

A number of organs removed at necropsy were also examined for virus, precautions having been taken against accidental contamination from the skin. Fragments were ground up, cultured on blood agar, and extracted with M-250 phosphate buffer $p H 7 \cdot 2$ containing 100 units per $\mathrm{ml}$. of penicillin and streptomycin. The extracts were then inoculated on to the chorio-allantoic membrane of chick embryos. Unfortunately most of the organs (lung, liver, spleen, kidney, brain) were so heavily contaminated with Bact. coli that the embryos died. Surprisingly, however, the extract of an axillary lymph node and of the bone marrow were bacteriologically sterile, and on egg culture the bone marrow extract yielded 100 lesions per egg (i.e. approximately 1,000 infective particles per gramme of marrow) and the lymph node extract produced semi-confluent lesions (corresponding to 10,000 particles per gramme).

Vaccinia virus was also recovered at necropsy from the skin lesions.

The cerebrospinal fluid was sterile on bacteriological culture and no virus was recovered from it.

The serum samples obtained from the baby on various dates were stored at $-78^{\circ} \mathrm{C}$ and later tested for virus neutralizing antibodies. Mixtures of the various samples of serum and a known fixed quantity of virus were inoculated on to the chorio-allantoic membranes of groups of 
six 12-day-old chick embryos. The reduction in the number of pocks resulting from the inoculation of virus-serum mixtures made with immune sera compared with those made with normal serum from an unvaccinated subject was used as a measure of the antibody content of the sera under test. For these tests smallpox virus was used. It was desirable not to use vaccinia virus in these tests since some of the serum samples to be tested already contained vaccinia virus (see above).

The method of testing for serum antibody has been published elsewhere (McCarthy and Downie, 1948). In addition the samples were also tested unheated after storage at $-78^{\circ} \mathrm{C}$.

The samples tested were obtained on December 13, $18,23,31$, and January 7 , and of these only that taken on December 23 showed any neutralization. This sample neutralized over $75 \%$ of the virus in the test, but it is virtually certain that the antibody present came from the immune serum which had been given 18 hours previously. It is interesting that this passive antibody was no longer detectable in a sample taken on December 31, nine days after the serum had been given. Immediately after taking this sample $250 \mathrm{ml}$. of immune whole blood was given to the child and a few days later $750 \mathrm{mg}$. of gamma globulin. In spite of this the blood taken at necropsy on January 7 had no detectable antibody.

It was found that the unheated serum from the baby did not by itself neutralize variola virus and therefore lacked the natural antibody-like factor described by McCarthy and Germer (1952). The sample taken on December 18, that is before any transfusions had been given, was nevertheless able, when incorporated in virusimmune serum mixtures, to increase twentyfold the neutralization of variola virus by a heated immune serum. It therefore possessed the second or potentiating factor described by McCarthy and Germer.

Finally the vaccinia virus recovered from the bone marrow of the infant at necropsy was itself tested in neutralization tests on the chorio-allantois and shown to be readily neutralizable by anti-vaccinial rabbit serum. Further, this virus was also neutralized by serum from the two donors, serum given on December 22 (A) and blood on December 31 (M) (Table 1). The degree of neutralization of this virus did not differ from that of a stock

\section{TABLE 1}

NEUTRALIZATION TEST USING SERA FROM TWO DONORS AND NORMAL (UNVACCINATED) HUMAN SERUM AGAINST PATIENT'S VACCINIA VIRUS

\begin{tabular}{l|c|ccc}
\hline \multicolumn{1}{c|}{ Sera } & \multicolumn{2}{c}{$\begin{array}{c}\text { Pock Counts on } \\
\text { Individual Eggs }\end{array}$} & & $\begin{array}{c}\text { \% of Virus } \\
\text { Surviving }\end{array}$ \\
\hline Normal human serum & $\cdots$ & $20,40,62,64,65$ & 100 \\
Serum from donor M & $\cdots$ & $6,12,18,30,54$ & 48 \\
Serum from donor A & $\cdots$ & $9,18,20,20,25$ & 36 \\
\hline
\end{tabular}

strain of vaccinia virus derived by egg culture from a vaccination lesion in a normal adult (Table 2 ). The possibility that the virus might have become resistant to neutralization by immune sera can therefore be excluded.
TABLE 2

NEUTRALIZATION TEST USING SERA FROM TWO DONORS AND NORMAL (UNVACCINATED) HUMAN SERUM AGAINST STOCK STRAIN OF VACCINIA VIRUS

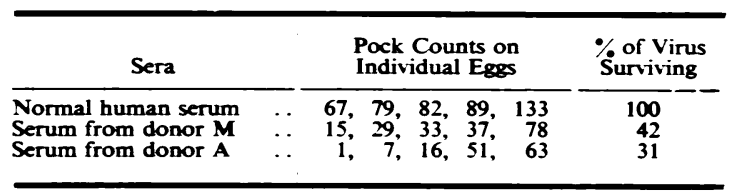

While we were preparing this paper our attention was drawn to the report by Bruton (1952) of a case of recurrent infection over a period of four years in a young boy in whom failure of antibody production was found to be associated with complete absence of gamma globulin in his serum. A specimen of serum from our case which had been obtained on December 31 (before the transfusion of whole blood) and had been stored at $-78^{\circ}$ C. for seven months was sent to Professor $\mathbf{R}$. A. Kekwick for electrophoretic analysis. His report, together with normal values for newborn infants, is given in Table 3.

TABLE 3

ELECTROPHORESIS ANALYSIS

\begin{tabular}{|c|c|c|}
\hline & $\begin{array}{l}\text { Electrophoresis Values } \\
\text { for E.H. }\end{array}$ & $\begin{array}{c}\text { Approximate Normal } \\
\text { Values for Newborn } \\
\text { Infants* }\end{array}$ \\
\hline $\begin{array}{l}\text { Total protein } \\
\text { Albumin } \\
\text { Globulin } \\
\text { Alpha } \\
\text { Beta }\end{array}$ & $\begin{array}{l}4.54 \mathrm{~g} / 100 \mathrm{ml} \text {. } \\
52 \cdot 2 \% \text { of total protein } \\
24.4 \% \text { of total protein } \\
23.5 \% \text { of total protein } \\
0.0 \% \text { of total protein }\end{array}$ & $\begin{array}{l}6 \mathrm{~g} / 100 \mathrm{ml} \text {. } \\
64 \% \text { of total protein } \\
13 \% \text { of total protein } \\
10 \% \text { of total protein } \\
16 \% \text { of total protein }\end{array}$ \\
\hline
\end{tabular}
(1945)

- Calculated from data given by Longsworth, Curtis and Pembroke Discussion

It has been shown that a viraemia frequently occurs after primary vaccination (Herzberg-Kremmer and Herzberg, 1930-31) and it is, therefore, not surprising that in people whose skin is already damaged by atopic eczema or other skin disease, by burns or by varicella, widespread lesions may occur. Generalized vaccinia occasionally develops in individuals whose skin was previously undamaged. The course of the disease is then very similar to smallpox, the lesions appearing in one crop about eight to 12 days after vaccination. Virus-neutralizing antibody has been demonstrated in such cases (McCarthy, 1951).

In a very few cases widespread cutaneous lesions continue to appear over several weeks; they do not go through the normal stages of development and they fail to heal. The primary lesion develops at the normal time after vaccination but also fails to heal and secondary lesions may appear around its periphery. Nearly all of these cases have been fatal.

Acland and Fisher (1893) described such a case in a 3-month-old infant vaccinated by the arm-toarm method, the lymph being derived originally from 
a calf but having had 41 human passages before this vaccination. On the fourteenth day after vaccination a large sore developed at the vaccination site and scattered lesions were present on the face, lips, trunk and extremities. Lesions continued to appear for five weeks and the child eventually died 49 days after vaccination. Throughout the course of the disease no enlargement of the lymph nodes was noted and there was little or no fever. Shortt (1933) and Dible and Gleave (1934) reported another case which was very similar to the one recorded here. The child was 3 months old and generalized lesions developed 16 days after vaccination, death occurring 10 days later. At necropsy necrotic areas were found in the liver and spleen which, on section, showed no inflammatory reaction. The histology of the skin lesions resembled that in the present case, the notable features being the absence of inflammatory reaction and the large number of cytoplasmic inclusion bodies. No antibody studies were carried out in their case. Bigler and Slotkowski (1951) described a case of generalized vaccinia in a Negro girl who had been unsuccessfully vaccinated in infancy. She was revaccinated at the age of $5 \frac{1}{2}$ years on the left arm and five weeks later there was a necrotic ulcer at the vaccination site. Ten weeks after vaccination umbilicated, vesicular lesions appeared on the shoulder, back, face and hand. The left arm became gangrenous before death. Laurance, Cunliffe and Dudgeon (1952) have recorded another case in an infant of 4 months who died after a course of 89 days. In 1944 Crosbie and Downie (personal communication) saw a child who had been vaccinated at the age of 11 months and in whom lesions continued to develop until death occurred from intercurrent infection two months later. Laurance et al. (1952) mention, without giving details, two additional cases, one of which recovered. Thus of the eight cases of which we have knowledge, seven have been fatal.

The main feature which distinguishes these cases from most cases of generalized vaccinia and of eczema vaccinatum is the prolonged course, during which lesions continue to develop and fail to heal. In the course of a normal vaccination virusneutralizing antibody appears in the blood at about 12 to 14 days and continues to rise until about three weeks when it attains a steady level. Antibody probably develops in the cells at an earlier stage at the time when the primary lesion begins to heal, i.e. about eight to nine days. In most cases of generalized vaccinia cutaneous lesions develop as a single crop about eight days after vaccination. HerzbergKremmer and Herzberg (1930-31) showed that the viraemia following primary vaccination usually occurs at about the sixth to eighth day. When metastatic lesions occur they would then take another two to three days to develop. By that time the accumulation of virus-neutralizing antibody in the blood would prevent the development of further lesions and would aid the healing of those which were already present. If antibody did not develop, the viraemia would persist unchecked and the healing of metastatic lesions might be impaired. In the case reported by Laurance et al., in Crosbie and Downie's case, and in our own, failure of antibody production was demonstrated and it is probable that there was a similar failure in the other five cases listed above.

A noteworthy feature of our case was the profound lymphopenia (120 lymphocytes per c.mm.). Associated with this was the remarkable absence of lymphocytes in the sections of spleen and lymph node which were examined. Monocytes and plasma cells were present in abundance. The recent work of Fagraeus (1948) suggests that the plasma cell is the principal cell responsible for antibody production. It is, therefore, interesting that in this case failure of virus-neutralizing antibody production was associated with the presence of abundant plasma cells in the reticulo-endothelial system whereas lymphocytes were almost impossible to find. As the peripheral blood counts were only performed after the transfusion of whole blood it is possible that the scanty lymphocytes which were present in the child's blood may have been derived from the donor's blood transfused the previous day, the donor having been bled three hours before transfusion.

The complete absence of gamma globulin in the single specimen of serum that was examined is of interest in view of the report of Bruton (1952) of a child who was unable to form antibodies despite repeated exposure (both accidental and deliberate) to a variety of antigens and who was found to have a complete absence of gamma globulin in a number of specimens of serum that were examined. In our case tests against antigens other than variola virus were not made, but the complete absence of detectable neutralizing antibody for variola virus taken in conjunction with the absence of gamma globulin would suggest that the child would have been unable to form serum antibody against any other antigen.

Treatment of such cases remains unsatisfactory. In the absence of effective treatment a fatal outcome seems almost certain. Immune serum from recently vaccinated individuals has proved disappointing in the doses which have been used. We have shown that neutralizing activity rapidly diminished and after nine days was no longer detectable in the serum. It would, therefore, seem that hyperimmune animal 
sera or convalescent serum from a recent case of smallpox should be given in large doses at frequent intervals. The possibility of replacement transfusions should be seriously considered if serum is not available.

\section{Summary}

A fatal case of generalized vaccinia in a baby is described. Secondary lesions developed two weeks after vaccination and fresh lesions continued to appear until death occurred five weeks later.

No neutralizing antibodies for vaccinia virus could be demonstrated in the child's serum and electrophoretic analysis showed complete absence of gamma globulin.

We should like to thank Dr. R. W. Brookfield for permission to investigate this case, Professors N. B. Capon and A. W. Downie for their advice, Dr. E. G. Hall for the report on the post-mortem examination and Professor R. A. Kekwick for the electrophoretic analysis of the serum.

\section{REFERENCES}

Acland, T. D. and Fisher, C. H. (1893). Trans. clin. Soc., Lond., 26. 114.

Bigler, J. A. and Slotkowski, E. L. (1951). Pediatrics, 7, 24.

Bruton, O. C. (1952). Ibid., 9. 722.

Crosbie W. E and Downie, A. W. (1944). Personal communication. Dible, J. H. and Gleave, H. H. (1934). J. Path. Bact., 38. 29.

Fagraeus, A. (1948). Acta. med. scand., Suppl. 204.

Herzberg-Kremmer, H. and Herzberg, K. (1930-31). Zbl. Bakt. 1. Abt. Orig., 119, 175.

Laurance, B., Cunliffe, A. C. and Dudgeon, J. A. (1952). Archiveslof Disease in Childhood, 27, 482

Longsworth, L. G., Curtis, R. M. and Pembroke, R. H. (1945). J. clin. Invest., 24, 46.

McCarthy, K. (1951). M.D. Thesis. Univ. Liverpool.

and Downie, A. W. (1948). Brit. J. exp. Path., 29. 501.

and Germet, W. D. (1952). Bbid. (In the press.)

Shortt, C. J. de Vere (1933). Brit. med. J., 1, 1004. 